\title{
Suárez y quienes negaron el intelecto agente en el s. XVI
}

Suárez and who denied the agent intellect in s. XVI

\section{JUAN FERNANDO SELLÉS DAUDER}

Universidad de Navarra. Facultad de Filosofía y Letras

jfselles@unav.es

Resumen. En este trabajo se estudian tres tesis de diversos autores renacentistas sobre el intelecto agente: a) la de quienes negaron la distinción real entre uno y otro intelecto: Jacques Lefèvre d'Étaples, Francisco Suárez y Gabriel Vázquez. b) La de los que admitieron sólo una distinción formal o de razón: Felipe Melanchton, Juan Velcurio y Rodolfo Goclenio. c) La de quienes aceptaron sólo una distinción nominal: Gómez Pereira, el Brocense, Juan Eck y Agustín Faba.

Palabras clave: intelecto agente; negación; formalismo; nominalismo.

Abstract. In this paper three theses on the agent intellect of various Renaissance writers are studied: a) those that deny the real distinction between one and another intellect: Jacques Lefèvre d'Étaples, Francisco Suárez, and Gabriel Vázquez. b) those who admitted only a formal distinction: Philip Melanchthon, John Velcurio and Rudolph Goclenius. c) those who accepted only one nominal distinction: Gómez Pereira, the Brocense, John Eck and Augustin Faba.

Keywords: Agent intellect; denial; formalism; nominalism. 


\section{Introducción}

Como es sabido, el Estagirita expuso su hallazgo sobre el intelecto agente humano, distinto realmente del posible, en su tercer libro De anima (Aristóteles 1960; c. 5, 430a 10-24). Este es un hallazgo de primera magnitud, porque -de admitir la distinción real tomista entre acto de ser y esencia y distinguirla en el hombre-, dado que el intelecto posible o paciente, por potencial, pertenece a la essentia hominis, el intelecto agente, por nativamente activo, debe formar parte del actus essendi hominis (Sellés 2012).

En suelo europeo, escribieron comentarios o cuestiones al De anima durante el siglo XVI muchos autores. Pero el Renacimiento contó también con pensadores que atacaron abiertamente la doctrina aristotélica. Otros pensadores de esta centuria, de los que nos ocuparemos en esta investigación, trabajaron los textos aristotélicos, pero los interpretaron a su modo, en concreto y respecto del tema que nos ocupa, algunos de ellos negaron la existencia del intelecto agente; otros, sólo admitieron una distinción formal de él respecto del posible; y unos terceros, sólo una distinción nominal.

Por tanto, dividiremos este estudio en tres partes: a) una dedicada a pensadores que negaron la existencia del intelecto agente: Jacques Lefèvre d’Étaples, Francisco Suárez y Gabriel Vázquez; b) otra, a aquellos que entre ambos intelectos sólo admitieron una distinción formal: Augustini Bucci, Felipe Melanchton y Rodolfo Goclenio; y la tercera, para aquellos que sólo admitieron una distinción nominal entre ambos intelectos: Gómez Pereira, el Brocense, Juan Eck y Agustín Faba.

\section{Negación del intelecto agente}

\subsection{Jacques Lefèvre d'Étaples (1450-1537): sin distinción}

También conocido como Jacobus Faber Stapulensis, fue el pensador francés al que se le considera fundador del humanismo renacentista en este país. Fue traductor directo y comentador de Aristóteles. Se conserva una obra suya titulada In hoc opere continetur totius philosophiae naturalis paraphrases, es decir, la Física, el De coelo et mundo, De generatione et corruptione, Metheorum, 
De anima, De sensu et sensato, De memoria et reminiscencia, De somno et vigilia y De longitudine et brevitate además de un Dialogus. La obra, en latín con caracteres antiguos y abreviaturas, es de dificultosa lectura. Su cap. V del libro III De anima se compone de tres conclusiones, que explica brevemente, y una especie de corolario o paráfrasis.

La primera conclusión dice que "el alma es en cierto modo todas las cosas". La segunda, que "la misma naturaleza del alma no existe con materia". La tercera, que "de las cosas sensibles y lo que sin magnitud no se percibe, son inteligibles las especies sensibles separadas de la materia” (A, III, 210). En la paráfrasis explica cómo entiende las especies sensibles y las del intelecto. Indica asimismo que el intelecto forma nociones abstractas derivándolas, abstrayéndolas, de las especies sensibles concretas (A, III, 210 ), pero en modo alguno distingue entre intelecto agente y posible, sino que comenta este pasaje de modo nuevo, en general (A, III, 211-2). Lo que precede indica que estamos ante un autor que ha abandonado la anterior manera de llevar a cabo la exégesis de los textos de las “autoridades”, forma muy analítica y pegada a las palabras, y sigue otra libre, moderna, liberal.

\subsection{Francisco Suárez (1548-1617): como la razón es espontánea, sobra el intelecto agente}

Como es sabido, este jesuita granadino fue un comentador sui generis de Tomás de Aquino, pues no siempre siguió la doctrina tomista, sino que se separó de ella en puntos centrales. En la obra completa del Doctor Eximio encontramos en el volumen 3 un lugar central de cara a nuestro tema: el largo capítulo titulado An sit necessarius intellectus agens, seguido de otro secundario bajo el título Utrum intellectus noster pro hoc statu pendeat in operatione sua ab operatione phantasiae. Además, en el tomo 25 hay una escueta referencia al intelecto agente cuando trata de la unidad formal, más dos en el 26, al hablar de la división de los nueve accidentes y de la cualidad. Resumamos la doctrina suareciana al respecto (Grau 2002; Sevilla 2006).

El primer pasaje aludido aparece en el libro De potentia intellectiva, cuyo capítulo II pregunta: Utrum ad productionem specierum intelligibilium admitere oporteat intellectum agentem. Suárez parte de que "dado que el intelecto no 
se mueve sino por el objeto interior representado en la fantasía, al ser el fantasma material, no puede por tanto obrar las especies espirituales en el intelecto espiritual; en consecuencia, hay que buscar un principio que lo acomode, al cual llaman intelecto agente" (Suárez 1859, 716 a). Adviértase que apela al intelecto agente como requisito para pasar del conocer sensible al intelectual, de modo que la comparecencia del intelecto agente queda enmarcada exclusivamente en la abstracción. En el siguiente punto niega la teoría noética de Platón y defiende la de Aristóteles. A continuación expone que Durando e Isaac de Narbona negaron la existencia del intelecto agente. Seguidamente ofrece la vera resolutio coincidente con el parecer de Cayetano, a saber, la necesidad de poner una virtud espiritual que, concurriendo con los fantasmas, haga inteligibles las especies. Con todo, cómo sea esa concurrencia, auctores disputant -añade Suárez-, y aunque él le dedica varios epígrafes, no vamos a detenernos en ella porque no es el punto central que nos ocupa, sino el de la distinción entre ambos intelectos. Con todo, en la explicación del cometido abstractivo del intelecto agente, hay que decir que un punto a favor del parecer suareciano consiste en sostener que "toda la acción del intelecto agente es espiritual; por tanto no inmuta realmente nada” (Suárez 1859, 717 a).

J. M. Alejandro, un buen estudioso de Suárez, que cuenta con muchos trabajos sobre la gnoseología de este pensador renacentista, recuerda que, para el pensador granadino, el singular se puede conocer directamente; por eso el papel clásico del intelecto agente está de más. En el trabajo "Esencia y valor del conocimiento según el Dr. Eximio” de este estudioso, se indica que la teoría del conocimiento suareciana "significa la expresión más completa y exhaustiva del realismo gnoseológico, no diremos exclusivamente aristotélico, sino propio de todos los grandes filósofos hasta los primeros titubeos antimetafísicos de Descartes" (Alejandro 1948, 215) ${ }^{1}$. Para él este realismo radica en la pasividad del entendimiento, su absoluta dependencia

1 Más adelante añade que "la doctrina del Doctor Eximio sobre este tema crucial en toda filosofía (naturaleza y valor del conocimiento), es intrínseca y cordialmente escolástica, y sin decir ni mucho menos que señale una posición esencialmente distinta del tomismo, sí hay que afirmar que es característicamente propia”. Ibidem, 221. 
de los sentidos, y la actividad de las imágenes y del intelecto agente (Alejandro 1948, 216). Alejandro entiende la pasividad, en el sentido de que "la potencia ha de tener una iniciativa propia, por lo menos la iniciativa de la acción vital de la que es dueña” (Alejandro 1948, 223). En efecto, Suárez admitía que la potencia intelectual es potencia respecto de lo inteligible, pero por sí misma tiene actividad propia: "el entendimiento situado en el actu primo cognoscitivo, no necesita de motor extrínseco alguno para obrar... la potencia cognoscitiva posee una actividad inmediata y propia sobre su acto" (Suárez, 1859, III, 4, 10; IV, 2, 12). Por tanto, no hace falta esperar a la Crítica de la razón pura kantiana para leer en la modernidad que la razón es espontánea y se desencadena de suyo, asunto impensable para los filósofos medievales, quienes advirtieron que una potencia pasiva (tabula rasa) no se puede activar por sí sola. La facultad se activa -agrega Suárez- con el concurso (con-causalidad o cooperación) de la especie (tesis que ya defendió Escoto), pero la iniciativa es más de la potencia que de la especie, y no requiere de otro entendimiento (agente) que la active, pues el conocer de la potencia intelectual "tiene que proceder necesariamente a principio intrinseco activo” (Alejandro 1948, 226).

Como se puede apreciar, la similitud de la propuesta suareciana con la escotista -ratificada por J. M. Alejandro- es notable. En suma, "la potencia es poseedora de una energía vital que gravita hacia un objeto (intellectus naturaliter et vitaliter propensus), y sólo necesita un determinante encauzador de esa energía, que es la especie" (Alejandro 1948, 227). El conocer es una actualis assimilatio resultante de la unión del cognoscente a lo conocido. Según Suárez, no es que el acto de pensar forme o presente el objeto pensado, sino que es el mismo acto el que se asimila a lo real: "el hecho de conocer se da porque la misma potencia se hace en alguna manera la misma cosa vitalmente" (Alejandro 1948, 230)².

2 Más abajo agrega: "la potencia en el acto mismo de conocer se hace o se convierte en el mismo inteligible, y esta transformación no puede darse sino en cuanto la potencia es informada por la especie, que intencionalmente representa el objeto”. Ibidem, 231. 
Pero la precedente manera de entender el conocer humano conlleva una equiparación de él al modo de actuar de la voluntad, porque es claro que los actos de esta potencia son intencionales. De ser esta apreciación correcta, la hermenéutica suareciana del conocer incurriría -como la de Escoto- en un voluntarismo de fondo. Tal vez por eso Suárez niegue la distinción entre el acto de conocer y el concepto conocido, sosteniendo que el concepto es el mismo acto, $y$, al igual que en la voluntad, su acto no forma nada, sino que tiende directamente a lo real. Dada la concurrencia activa entre el fantasma y el acto de conocer de la potencia intelectual, pensar que el fantasma es pasivo y que requiere de un intelecto agente que lo universalice, según Suárez, hoc enim puerile est cogitare. A su vez, negada la distinción entre acto de pensar y concepto pensado, será el mismo acto el que conozca directamente lo real, sin mediación alguna. Pero esto es, en rigor, escotismo, que implica dos cosas, a saber: negación del intelecto agente, y espontaneidad noética de la razón (en concurso con los fantasmas) al modo de la espontaneidad que el Doctor Sutil admitía para la voluntad.

El que el intelecto agente universalice, para Suárez, es una hipótesis infantil, porque ya universaliza el posible. Le basta dedicarse a "producir” en el posible las especies inteligibles. Además, estima que no es cognoscitivo, y requiere una determinación del fantasma para la producción de la especie. Suárez niega que el intelecto agente ilumine el fantasma y afirma de él que produce la especie. Para Alejandro la propuesta suareciana es correcta, pero en modo alguno lo es. Por lo demás, este estudioso del Doctor Eximio nos facilita otra clave hermenéutica certera: la asimilación de la teoría del conocimiento de Balmes a la de Suárez (Alejandro 1948, 235 ss), pero la del novecentista es, en este punto, claramente nominalista.

\subsection{Gabriel Vázquez (1549-1604): no existe intelecto agente porque no se requiere para ver a Dios}

Vázquez, natural de Belmonte (Cuenca), jesuita, estudió en Alcalá, donde después sería maestro, así como en el Colegio Romano. A pesar de sus escasos 55 años de vida nos dejó muchos escritos (10 volúmenes en la edición de Lyon, de 1620), entre ellos el Commentarius et Disputationes in 
Primam Partem Summae Sancti Thomae per priores XXVI, Quaestiones de Deo, de Praedestinatione, A Quaestione XXVII usque ad LXIV, De Trinitate et de Angelis, lugar donde estudia el intelecto agente. Se podrían también tener en cuenta sus Disputationes metaphysicae, pero este libro está conformado por una selección de textos filosóficos extraídos de otras obras suyas.

Aunque ya otros se han pronunciado sobre nuestro tema de estudio en este autor (Baciero 2006), vamos a centrar la atención directamente en los pasajes en los que Vázquez estudia el intelecto agente. En el Index del Comentario a la I ${ }^{a}$ Parte de la Summa de la edición que cotejamos (el cual aparece al final de la obra) seleccionamos estos ítems: Disp. 45, $\mathrm{n}^{\circ} 2$ ) Intellectus agens non distinguitur realiter a possibili; Ibid., nn. 2-3) Qua ratione intellectus agens et possibilis dicantur lumen; Ibid., $\mathrm{n}^{\circ} 3$ ) Intellectus agens quomodo illustrat phantasmata. El primer ítem está incluido en la cuestión en que se debate "si al margen de la luz de la gloria es necesaria la luz del intelecto agente para ver a Dios”. En el capítulo I de la Quaestio XI Vázquez aporta las opiniones de dos escolásticos: Capreolo y Ricardo³. Según el primero la luz de la gloria no se infunde en los bienaventurados al intelecto agente, porque como el papel de éste es abstraer, para ver a Dios no hace falta abstraer ninguna especie. En cambio, para Ricardo son necesarias la luz de la gloria y la del intelecto agente para ver a Dios; por tanto, se requiere de una y otra, aunque en primer lugar la luz de la gloria, y en segundo, la luz del intelecto agente (Vázquez 1598, 348 a).

En el capítulo II de esa misma Quaestio propone la opinio vera respecto del tema en cuestión, para lo cual debe perfilar qué sea el intelecto agente ${ }^{4}$. A continuación escribe que "ciertos filósofos dijeron que el intelecto agente es una realidad distinta del posible y que le sirve a él, de modo que ilumina los fantasmas y de ahí abstrae las especies inteligibles” (Vázquez 1598, 348 a); lo cual, si fuese verdad -añade Vázquez-, no se requeriría para la

3 Capreolo (1380-1444) es un comentador tomista de primera hora. En cambio, Ricardo, tal vez sea el franciscano Ricardo Middelton o de Mediavilla (1250-1300). Esto es posible, porque se refiere a ambos como autores "escolásticos".

4 "Hic dificultati facile respondebimus si prius explicatum fuerit quid sit lumine intellectus agentis”. Ibidem. 
visión divina, ya que ésta no se recibe sino en el intelecto posible. Con todo, no fundamenta esta opinión. Por otra parte agrega que "otros aseguran que el papel del intelecto agente no es sólo abstraer las especies, sino también iluminar los principios" (Vázquez 1598, 348 a); pero en la visión de Dios -sigue el conquense- esta iluminación todavía tiene menos lugar.

"Pero si decimos -objeta Gabriel Vázquez- que es la misma facultad el intelecto agente y el posible, y por tanto que son del todo la misma luz, lo cual pienso que es verdad, entonces, sin duda, la luz del intelecto agente y la del posible se deben distinguir exclusivamente por el efecto. Pues como es espiritual la luz que ilumina espiritualmente algo, no será ciertamente otra cosa que lo que espiritualmente manifiesta. Pero toda manifestación e iluminación es así, y no puede ser entendida de otro modo o explicar el género de esta iluminación interior. Por tanto, la misma luz del intelecto se dice que es agente... Y se dice también luz del intelecto posible..." (Vázquez 1598, 348 b). En los puntos suspensivos Vázquez incluye muchas oraciones subordinadas que hemos omitido para que se entienda mejor su intención. En tales frases explica, en cada caso, por qué se llama "luz" del agente y por qué "luz" del posible. En el primer caso aduce -entre otras razones-, que el intelecto agente produce con el fantasma la especie inteligible del objeto; no porque ilumine al fantasma, sino porque con el fantasma -dice-ilumina y manifiesta el objeto. En el segundo caso, indica que la fuerza del posible produce con la especie la visión o el conocimiento del objeto, que es su manifestación o iluminación.

Tras lo que precede el Belmontano concluye la cuestión inicialmente propuesta diciendo que para ver a Dios no se requiere abstraer ninguna especie, lo cual es verdad, ya que en ese estado entre criatura espiritual y Creador sobra cualquier mediación. Con todo, que el intelecto agente no se distinga del posible no es correcto; no lo es tampoco que el papel del agente se reduzca a abstraer, y asimismo que la visión beatífica corra a cargo del posible, pues tal visión es "personal”, y es claro que la persona o acto de ser personal no se reduce a una potencia, como es la razón, o al conjunto de ellas, si es que se acepta la distinción real entre actus essendi y essentia en el hombre y se admite que persona equivale a acto de ser. 


\section{Formalismo}

En este apartado atenderemos a tres autores que sólo admitieron una distinción formal o de razón entre el intelecto agente y el posible, lo cual, si bien no constituye una negación explícita del intelecto agente, como se verá, en la práctica equivale a lo mismo.

\subsection{Felipe Melanchton (1497-1560): un solo conocer con múltiples oficios}

El discípulo más famoso de Lutero trata del intelecto agente y paciente en su comentario al libro De anima (Melanchton 1846, 147-149). Comienza por afirmar que "aunque son inmensas las polémicas sobre el intelecto agente y paciente, sin embargo, si tomamos distinción de las acciones, es simple y diáfana esta explicación” (Melanchton 1846, 147). Añade que "Aristóteles discierne dos oficios del intelecto, pero los oficios del intelecto son plurales... pues el intelecto toma los objetos, compone, divide, razona, juzga. En este razonamiento encuentra algo de algo otro. Este intelecto inventor, y como poeta se llama agente, o rectamente actuante. Otro oficio es entender, conocer, y como tomar dictados después de haber encontrado. Por este oficio se llama entendimiento paciente" (Melanchton 1846, 148). De momento la distinción entre ambos intelectos, para este discípulo de Lutero, parece de nombres, pues a las diversas funciones de la inteligencia se les llama de un modo u otro.

Melanchton indica también que, para el Estagirita, el inventar o descubrir es mejor. Por tanto, "más vale el intelecto que hace a los demás" (Melanchton $1846,148)$. Añade que el agente ayuda al paciente: "así como la luz ayuda a los ojos, así dijo (Aristóteles) que el intelecto paciente es ayudado por el que inventa... Además, dijo que abstrae de los fantasmas. Esto es, éste confiere velozmente los objetos" (Melanchton 1846, 148). Por otro lado, escribe que Aristóteles “añadió también que es separable, no mezclado, no sometido a alguna lesión o pasión, notas que algunos interpretan de la inmortalidad. Yo tampoco lo repugno... Dice Aristóteles: la mente viene de fuera... Cualquiera que fuese la sentencia de Aristóteles sobre el intelecto que 
hace y que padece -concluye Melanchton- ciertamente hemos distinguido rectamente las acciones: encontrar y tomar los dictados" (Melanchton 1846, 148-149). Como se puede apreciar, este autor conoce en cierto modo la doctrina aristotélica al respecto; también la de Averroes que, aunque ajena a la de Aristóteles, es comprensible (Melanchton 1846, 149), pero Melanchton descalifica las interpretaciones restantes (Melanchton 1846, 149), y concluye que los nombres de "posible" y "agente" responden a un solo conocer con múltiples oficios.

\subsection{Juan Velcurio (1490-1534): dos oficios y una esencia}

Ioannis Velcurionis escribió un pequeño librito titulado Commentariorum libri IIII in universam aristotelis Phisicen. Al final de la obra sigue un amplio índice analítico. Algunos capítulos del libro IV son interesantes para nuestro propósito: así, el XVIII, que está dedicado al alma racional; el XIX, al intelecto; el XX, a las especies inteligibles de las cosas materiales; el XXI, a las especies inteligibles de las realidades inmateriales; el XXII, a los universales, y el XXIII, a la razón. Sin embargo, sólo en el cap. XIX titulado De intelecto, se aborda el estudio del intelecto agente. Lo divide en tres partes: la primera la refiere al nombre del intelecto; la segunda, a indicar que el intelecto o mente es una potencia del alma racional; la tercera, a abordar la primera división del intelecto, a saber, entre agente y pasible. Resumamos su parecer respecto del intelecto agente, pero primero veamos cómo lo enmarca en su tratamiento de las potencias del alma: "Verdaderamente el intelecto se divide en dos, ya que tiene dos oficios, y no difieren en esencia entre sí. Pues el intelecto es uno y simple por sí indivisible por esencia, y estas dos serán aquella misma en número, aunque difieran por los oficios” (Velcurionis 1575, 463-464). Esto nos da a entender que para este autor no se da una distinción real entre el intelecto agente y el posible. Con todo, las exposiciones que añade no parecen responder a esta pauta inicial.

"La primera división es ésta -indica Velcurio-: doble es el intelecto, a saber, agente y pasible. El intelecto agente es una potencia del alma racional, cognitiva, que abstrae las especies inteligibles de los fantasmas y las transmite al intelecto pasible para que las reserve... De esta definición 
queda claro que dos son los oficios del intelecto agente, uno que se llama iluminar los fantasmas, esto es, abstraer la especie inteligible y claramente inmaterial de cualquier fantasma... Otro oficio es el que llaman iluminar al intelecto pasible, esto es, aquellas especies abstraídas de los fantasmas y juzgadas las imágenes por el intelecto agente son transmitidas al intelecto pasible no solo para conocerlas, sino también para conservarlas en la memoria, para restablecerlas" (Velcurionis 1575, 464-465). De este texto se deduce que para Velcurio el objeto del intelecto agente son las especies inteligibles, que sus oficios son dos: por un lado la abstracción; por otro, iluminar al intelecto posible.

Luego establece un par de comparaciones sugerentes: una, que "el intelecto agente es como un doctor que enseña, mientras que el pasible es como el discípulo que aprende" (Velcurionis 1575, 465); otra, que "en Homero, aquel Néstor prudentísimo entre los griegos es como el intelecto agente" (Velcurionis 1575, 465). Por otra parte, describe al intelecto pasible como potencia cognoscitiva del alma. En cuanto a la diferencia entre ambos intelectos escribe: "el intelecto agente es la causa eficiente que conoce la especie inteligible. Pero el pasible es como el sujeto o la materia, en el cual moran y residen las especies halladas" (Velcurionis 1575, 465). Y en cuanto a la superioridad de uno sobre otro añade que el pasible, como discípulo, es inferior al agente, que es como doctor, porque éste es el que inventa y descubre, mientras que aquél guarda y repite lo descubierto (Velcurionis 1575, 466): aguda comparación.

Por lo que se refiere a las notas que Aristóteles atribuyó al intelecto agente Velcurio escribe: "El agente es perpetuo e inmortal... esto es, siempre buscando, encontrando, pensando en algo y no durmiendo, como es el pasible, y como que dormita, mientras no reciba los dictados ajenos, los cuales fallan frecuentemente, si los recibe mal" (Velcurionis 1575, 467). Hasta donde se sabe, es la primera vez que se atribuye al intelecto agente el papel de buscador ("semper quaerens" dice el autor), nota de singular importancia, pues si el tema propio del conocer superior humano no puede ser lo inferior a él sino lo superior, y si el tema superior a él al que está llamado a alcanzar es sobremanera excelso, la clave de su conocer se puede describir como búsqueda. 
"Y esto es -concluye Velcurio- lo que se predica del intelecto agente, que tiene en propiedad hacer todas las cosas, o sea, encontrar e iluminar cualquier especie inteligible, para que sea vista por el pasible, como la luz ilustra los colores que no son visibles, para que se puedan ver... Así pues, el intelecto agente tiene acto, pero el pasible tiene potencia" (Velcurionis 1575, 467). Como se puede apreciar, del agente dice que tiene acto y no lo asimila a una potencia, como era y es usual entre los comentadores aristotélicos. Tampoco a un hábito, como algunos han hecho.

\subsection{Rodolfo Goclenio (1547-1628): intellectum patientem et agentem non differere realiter, sed ratione}

Este renacentista dispone de varias obras en las que trata del intelecto agente. Una de ellas lleva por título De intellectu, et aliis quibusdam (1589); otra, Adversaria ad exotericas (1594); otra, Physicae Disputationes septem libros distinctae (1598); y otra más, Physica Complete Speculum (1604).

$1^{\text {a) }}$ La primera obra, De intellectu, et aliis quibusdam, muy breve y sin paginación, está conformada por una serie de propositiones philosophicae referidas al intelecto humano. La $\mathrm{n}^{\circ} 11$ indica que en el intelecto existe una triple división: "(Primero) el intelecto es paciente y agente. Segundo, es contemplativo y activo. Tercero, una es la noesis ton adiairetón, otra es sinzetón, esto es, la inteligencia es doble, simple y compuesta”. La proposición n ${ }^{\circ} 19$ reitera la primera de las precedentes distinciones: "El intelecto es paciente y agente”. La $\mathrm{n}^{\circ} 20$ dice así: "El intelecto agente es el principio inteligente del alma que recibe en sí las formas y especies de las cosas”, pero esta segunda parte la sentencia no es correcta, porque no es el intelecto agente, sino el paciente, el que recibe en sí tales formas. La n ${ }^{\circ} 21$ declara: "Asimismo, es la virtud del agente por la cual todas las cosas se conocen”; la no 22 agrega: "Está unido con la imaginación, y usa los sentidos como instrumento"; la n 23 se formula así: "El intelecto agente es el principio inteligente del alma, que recibidas las especies por la mente pasible, y entendidas en potencia las hace entender en acto"; la no 24, y última referida a este tema, indica: "Así pues, para que el primero recibiendo haga todas las cosas, así este abstrae las especies de las cosas y las hace todas, esto es, hace que todas se entiendan”. 
$2^{\text {a) }}$ La segunda obra, Adversaria ad exotericas, es un pequeño tratado en el que habla de Dios, del alma humana y de alguna realidad física. Respecto del alma, tiene una doble cuestión titulada así: An sit necessarium ponere intellectum agentem. An intellectus agens recordetur eorum post mortem, quae in vita intellexit. Goclenio responde afirmativamente a las dos cuestiones. a) De la primera explica que nuestro intelecto a veces entiende y otras no, y para pasar de no conocer a conocer requiere ser activado, pues nada que está en potencia se activa a sí mismo; por eso el intelecto paciente requiere del intelecto agente (Goclenii 1594, 151). Añade que, como el agente es simple, es subsistente y separable del cuerpo, de tal manera que puede actuar sin el cuerpo sin tener que usar la fantasía (Goclenii 1594, 152). Explica asimismo que la fantasía no puede por sí misma, sin la intervención del intelecto agente, producir la especie inteligible, pues eso es misión del agente (Goclenii 1594, 152-153). Éste también perfecciona al paciente, porque le ofrece las especies para entender (Goclenii 1594, 153). Revisa la objeción de Durando, quien negaba la existencia del intelecto agente bajo el pretexto de que tampoco se requiere de un "sentido agente”, respondiéndole con Tomás de Aquino, quien decía que no sucede en el sentido lo mismo que en el intelecto, pues en el primero son las mismas cosas sensibles las que producen la especie sensible, mientras que en el intelecto no pueden producir las inteligibles porque éstas son universales y aquellas particulares (Goclenii 1594, 154). b) En cuanto a la segunda cuestión indica que para Aristóteles el intelecto agente no es corruptible, como lo son las potencias orgánicas, pero sí lo es el paciente, por su unión con ellas (Goclenii 1594, 155-156). Pero esto último no es correcto. Aduce el testimonio contrario de San Agustín, para quien tras la muerte el alma también siente. Rodolfo Goclenio piensa que tras esta vida el alma conocerá de modo distinto, pues no tendrá necesidad de convertirse a los fantasmas (Goclenii 1594, 158). Otra cuestión que se plantea en esta obra es asimismo doble, y lleva este encabezamiento: An agens et patiens intellectum sit unus et idem et quomodo patiens sit alter non alius a seipso. $\mathrm{Su}$ respuesta es: "el intelecto paciente (o potencial, o pasible, o que padece) y el agente no difieren realmente, sino por la razón” (Goclenii 1594, 217), 
como difieren -dice- el agua cálida y la fría; pues el cambio en la cualidad no cambia la sustancia sino el accidente.

$3^{\text {a) }}$ La tercera obra, Physicae Disputationes septem libros distinctae, es un tratado más largo, con un amplio índice de materias, que versa sobre la naturaleza de la realidad física, pero al final tiene un pequeño tratado $D e$ anima en el que estudia las facultades del alma humana. No obstante, en esta obra no hay alusión alguna al intelecto agente.

$4^{\mathrm{a}}$ ) La cuarta obra, Physica Complete Speculum, más amplia que la precedente, y asimismo con más extenso índice, trata sobre todo de realidades físicas muy concretas, pero tiene unas breves alusiones a Dios y al alma humana al inicio. Tampoco en esta obra hay mención del intelecto agente, salvo media página en la que se dice, contra Averroes, que las almas son muchas en número, pero "si una y la misma fuese el alma en todos los hombres, innumerables personas serían un solo hombre. Sed non hoc. Ergo nec illud" (Goclenii 1604, 69). En suma, Goclenio admite que el intelecto paciente y el agente no difieren realmente sino sólo según la razón.

\section{Nominalismo}

\subsection{Gómez Pereira (?1500-1558) y el Brocense (1523-1600): absurdo o ficción}

Gómez Pereira en su célebre Antoniana Margarita escribió: "Absurdo es suponer que tengamos la facultad de sacar lo espiritual de lo corpóreo. Como los agentes intelectuales no obran sobre la materia, es imposible que de la conjunción entre el fantasma corpóreo y una forma intelectual, como es el alma, resulte un ser incorpóreo" (Menéndez Pelayo 1955, 265). Como se ve, para este autor no hay dimensión distinta del entendimiento o razón para activar su conocer, al que, por cierto, identifica con el alma. Más claramente: "el alma, como activa, es entendimiento agente; como pasiva, es intelecto posible” (Menéndez Pelayo 1955, 270).

Del mismo estilo fue también Francisco Sánchez de Las Brozas, llamado "el Brocense", que en un libro titulado Quod nihil scitur escribió: "A esto se añade la ficción aristotélica de universales, no menos vacía que la de las 
ideas platónicas; y esa nueva quimera del entendimiento agente, abstrayente e iluminante, que más bien llamaríamos oscureciente" (Menéndez Pelayo 1955, 239). Como se puede apreciar, estos pensadores son claramente nominalistas, pues -como en su día Ochkam- sólo admiten una distinción nominal entre ambas dimensiones noéticas humanas.

\subsection{Juan Eck (1486-1543): idem est intellectus agens et possibilis}

Este autor, célebre por sus polémicas con Lutero y Melanchton, y defensor de la ortodoxia católica en Alemania, tiene un libro titulado Aristotelis Stagyritae Philosophi De anima en el que dedica un capítulo al tema del intelecto posible y agente. En el primero, tras reproducir el texto aristotélico, añade una explicación del texto (explanatio textus); más abajo, unas notas (annotatio); seguidas de una explicación escolástica (explicatio scholastica); y más abajo la opinión del propio Juan Eck (sententia Aristotelis de intellectu mirifice declarata ab Eckio) escrita, como al final de este pasaje se declara, en 1518. A ese capítulo siguen cuatro artículos: en el primero pone tres notas; en el segundo, una conclusión; en el tercero, cuatro dudas, la última de las cuales versa acerca de si el intelecto agente y el posible se distinguen An intellectus agentis et possibilis distinguantur; y en el cuarto y último, una pregunta, su respuesta y asimismo la respuesta a las objeciones. Como se ve, la estructura de su trabajo es complicada. Resumamos sus alusiones al intelecto agente.

En la explanatio textus $\mathrm{n}^{\circ} 4$ sostiene que "el intelecto es de doble naturaleza, a saber, agente y posible, ya que el intelecto no es en acto nada de esas cosas que entiende antes de su intelección” (Eck 1520, folio XLIX, a). En el no 11 añade "la duda de cómo el intelecto conoce, si está al margen de la pasión como dijo Anaxágoras, y entender es cierto padecer. Responde que el intelecto es algo común al intelecto agente que actúa y al posible que padece" (Eck 1520, folio XLIX, b). En el nº 14 agrega que "en el alma se da el intelecto posible y el agente; se prueba en que en toda naturaleza hay algo como la materia y la potencia y algo como el acto y lo eficiente" (Eck 1520, folio XLIX, b). El n 15 sigue así: "Porque hay algún intelecto que se hace 
todas las cosas, y otro que hace todas las cosas; el primero se llama intelecto en potencia; el otro agente" (Eck 1520, folio XLIX, b). El n 16 ofrece las notas del intelecto agente: "El intelecto agente es separable, impasible, inmixto, acto, más noble que el posible, es inteligente e inteligible, es posterior al intelecto posible, no de modo simple, sino según el tiempo, ya que primero es el intelecto en potencia. Y que es más noble lo prueba diciendo que lo activo supera a lo pasivo" (Eck 1520, folio XLIX, b). Por último, el $\mathrm{n}^{\circ} 16$ añade: "Por qué no recordamos tras la muerte: porque el intelecto separado es verdaderamente impasible e inmortal, mientras que el intelecto pasivo que recuerda se corrompe" (Eck 1520, folio XLII a).

En las annotatio Juan Eck comienza diciendo que el pasaje aristotélico en cuestión es “oscuro", por lo que va a seguir la interpretación de Alejandro de Afrodisia, ya que -según él- lo entendió mejor que los demás, pues Averroes dijo muchas “cosas absurdas”, mientras Jerónimo Donato Véneto lo hizo bien. Añade que los primeros comentadores de Aristóteles pensaron que aquí hablaba del intelecto imparticipado o divino, pero Jámblico les contradijo (Eck 1520, folio XLII, a). En la explicatio scholastica este autor nos dice que va a exponer el parecer de Alejandro de Afrodisia, Temistio, Simplicio, Averroes, Ammonio, Alberto Magno, Tomás de Aquino, Egidio Romano, Juan el Gramático, Juan de Jandún, Avicena, Alfarabí, Avempace, Nicoleto Vernias, Agustino Nifo, Algacel, Besarión y otros (Eck 1520, folio XLII, b).

Luego, en el apartado sententia Aristotelis de intellectu mirifice declarata $a b$ Eckio señala que Averroes erró al sostener que existe un solo intelecto para todos los hombres, como explicaron Temistio, Lefèvre d'Étaples y Augustino Nifo. De opinión contraria a estos últimos es la de Marsilio Ficino, opinión que es común entre los pensadores griegos y árabes. Por su parte, el n 14, comienza así: "El alma inmortal tiene en sí dos potestades, a saber, el agente y el posible. Se llama intelecto posible no porque reciba las especies en esencia, sino porque es similar al que recibe, porque entiende de nuevo en acto. Y puesto que es lo mismo con el agente (et quia idem est cum agente), por esencia no se corrompe, como concluye Alejandro de Afrodisia. Respecto de esto se debe tomar la palabra de Temistio y de Ammonio de 
que el alma se compone de materia y forma, no como las toman el vulgo, sino porque lo mismo es el intelecto que hace todos los inteligibles y el que se hace todos (idem est intellectus qui facit omnia intelligi, et fit omnia)" (Eck 1520, folio XLIII, a).

A continuación, en su explicación del n ${ }^{\circ} 15$ agrega: "Se sigue que según los peripatéticos hay un triple intelecto en el hombre, a saber, el agente, el posible y el material, que es la misma alma cogitativa. Los dos primeros son incorruptibles, el tercero, que es engendrado y caduco, nace con el cuerpo y con él se disipa" (Eck 1520, folio XLII, c), asunto que es correcto. Más abajo, en el $n^{\circ} 31$, sigue diciendo que los recientes autores alemanes no admiten de Aristóteles dos intelectos en el hombre, como lo hicieron los autores franceses e ingleses (Eck 1520, folio XLIV, c). En el 33 indica que el que tras la muerte no recuerde hay que entenderlo en el sentido de que se corrompe el intelecto pasivo, material o común, es decir, la cogitativa. Luego ofrece los pareceres de diversos comentadores aristotélicos en torno a en qué consista la felicidad con la separación del intelecto tras la muerte, pero no alude en concreto al intelecto agente.

Tras esta exposición, centrada en las interpretaciones de los antiguos, Juan Eck aborda el comentario de este texto aristotélico según la opinión de los autores recientes. En el artículo I, en el que menciona a Juan de Buridán, Enrique de Gante y Godofredo de Fontaines, sostiene que el cuerpo puede incidir directamente en el espíritu y que, por tanto, los sentidos pueden inmutar al intelecto, hasta el punto que, lesionado el órgano de la fantasía, el intelecto no puede conocer, del mismo modo que la corrupción de la memoria sensible -según afirma-impide el acto racional (Eck 1520, folio XLIV, d). Este planteamiento, del que cita como fuente a Escoto, es ya netamente moderno. En el artículo II concluye que el intelecto es una virtud pasiva que no se corrompe. El III está conformado por 4 dubium. En el I ${ }^{\circ}$, en el que alude a Ockham, Gregorio de Arimini y Juan de Jandún, se pregunta si el intelecto requiere, antes de conocer, ser despojado de la naturaleza de las formas materiales. Su respuesta, en la que sigue a Averroes, es afirmativa. En el $\mathrm{II}^{\mathrm{o}}$ pregunta si el intelecto es forma sustancial del cuerpo. En el III ${ }^{\circ}$, si es perpetuo. 
El artículo $\mathrm{IV}^{\mathrm{o}}$, en el que nos vamos a detener, lleva por título An intellectus agens et possibilis distinguantur. En la premisa $3^{\text {a }}$ escribe que "según Aristóteles el intelecto posible es doble, uno propiamente inmaterial y perpetuo, que es el lugar de las formas y de las especies de todas las cosas inteligibles; y otro es el intelecto común, al que algunas veces llama pasivo por el hecho de que padece al recibir las especies inteligibles y las intelecciones. Los que no atendieron a esto opinaron cosas muy diversas, pues Egidio y Tomás Argentina entendieron que el intelecto posible es incorruptible; Juan de Jandún, que el agente es incorruptible; Escoto trató de uno y otro intelecto" (Eck 1520, folio XLV, a). En la premisa $4^{\mathrm{a}}$ añade que "el intelecto agente es definido por Aristóteles por el que el alma es capaz de hacer todas las cosas. El posible, por el que el alma es capaz de hacerse todas... El intelecto agente produce las especies inteligibles irradiando su luz sobre las intenciones sensibles, pero el entendimiento posible las recibe así producidas. Los dos se refieren a la intelección, de modo que el intelecto que educe parcialmente la intelección se llama agente, y el que la recibe se llama posible" (Eck 1520, folio XLV, a).

Luego añade que al respecto hubo muchas sentencias, pues algunos como Tomás de Aquino y Egidio Romano admitieron que son dos intelectos realmente distintos; que Escoto dijo que son formalmente distintos; que Buenaventura y Tomás Argentina sostuvieron que son dos dimensiones distintas. En cambio, "los recientes convencidos de que pluralitatis rerum absque necesitate establecieron que el agente y el posible son el mismo en esencia, pero que difieren por los nombres y oficios. Pero uno y otro son virtud no orgánica, impasible, inmaterial, inmixto, simple y eterno" (Eck 1520, folio XLV, d), acabando esta síntesis aludiendo a Ockham, Gabriel Biel y Cameracen -Pedro de Ailly-, (nominalistas) a lo que Juan Eck solo añade que "el intelecto no se llama inteligente por la producción de la intelección, sino porque la recibe, la cual él inmuta vitalmente” (Ibid.). Como se ve, el autor se va inclinando en este punto hacia el modo de pensar del nominalismo, lo cual no tiene apuro en declarar palmariamente en su conclusión: "el mismo es el intelecto agente y el posible: uno y el mismo es el que produce y el que recibe las especies inteligibles y las intelecciones” 
(Ibid.). En el artículo IV se pregunta cuatro cosas: a) si el intelecto es virtud pasiva. Responde que es impasible a la corrupción. b) Si se despoja de las especies materiales. Contesta afirmativamente. c) Si es forma sustancial del cuerpo humano. Replica que el cuerpo recibe el alma intelectiva. d) Si es corruptible. Alega que es virtud inorgánica.

De lo que precede cabe concluir, por tanto, dos cosas: una, que Juan Eck conoce la opinión de multitud de comentadores aristotélicos antiguos y recientes sobre el intelecto agente, aunque no siempre los interpreta correctamente; otra, que defiende a las claras la tesis nominalista.

\subsection{Agustín Faba (1569-?): sint subiecto idem}

Este comentador aristotélico publicó un amplio tratado de más de 450 páginas a doble columna titulado In tres Aristotelis libros De anima, que ofrece un índice de los capítulos al inicio y dos al final: uno analítico de términos y otro de sentencias. Su comentario al intelecto agente lo expone en el cap. II de su comentario al libro III (desde el texto 17 al 20), de la página 704 a la 713 inclusive. Comenta el texto aristotélico pormenorizadamente. Resumimos seguidamente su doctrina. Comienza indicando que va a seguir el orden en la exposición que ofrece Aristóteles: primero, la necesidad del intelecto agente; segundo, su naturaleza; tercero, su distinción del posible; cuarto, las propiedades de ambos. Son las cuatro partes en que se divide el texto aristotélico y en las que se verá que un intelecto es como la materia y el otro como la eficiencia; uno, pasivo; el otro, activo.

La paráfrasis aristotélica del texto 17 se refiere a la necesidad de que el intelecto agente exista: "Puesto que en la Naturaleza toda existe algo que es materia para cada género de entes... pero existe además otro principio, el causal y activo al que corresponde hacer todas las cosas -tal es la técnica respecto de la materia-”. Agustín Faba la ejemplifica con las semejanzas del herrero y del artesano, los cuales modelan diversos objetos materiales con sus acciones. Del texto: "También en el caso del alma han de darse necesariamente estas diferencias”, indica que es necesario que en el alma se dé un principio agente, no porque el alma tenga materia, sino porque tiene potencia, a saber, el intelecto posible; por tanto, debe tener también acto, esto es, el intelecto 
agente. Añade que como las especies en la materia son sólo inteligibles en potencia y son totalmente distintas del intelecto -como la causa material lo es de la eficiente-, se requiere de un acto que las haga inteligibles en acto, y este no puede ser el intelecto posible, porque es pura potencia; "por tanto es necesario que exista el intelecto agente" (Faba 1597, 706).

El texto 18 se centra en el estudio de la naturaleza del intelecto agente y comienza con la afirmación aristotélica siguiente: "Así pues, existe un intelecto que es capaz de llegar a ser todas y otro capaz de hacerlas todas", de la que Agustín Faba indica que con ella el Estagirita muestra que se da en el alma lo que el precedente texto exigía, a saber, que el intelecto posible es como la materia y el agente como la eficiente, y que el posible se reduce al acto por el agente; por lo cual se ve clara la necesidad de poner el intelecto agente. Añade que así como en el arte hay algo como la materia y algo como la eficiencia, así sucede en el alma, "hay un intelecto que es todos los inteligibles en acto, privado de por sí, reteniendo sólo la potencia de tomarlos, a saber, el posible... ante el cual se halla otro, que se llama eficiente, por el hecho de que tiene en acto las especies de las cosas" (Faba 1597, 706). Del texto "este último es a manera de una disposición habitual como, por ejemplo, la luz: también la luz hace en cierto modo de los colores en potencia colores en acto", Faba señala que el Estagirita compara uno y otro intelecto a la luz y los colores, de modo que "así como es necesaria la luz para que la vista vea, así es necesario en el alma el intelecto agente, por cuya obra el alma entiende en acto... de ese modo llama al intelecto agente como hábito, esto es, perfección respecto del posible, como la luz es en cierto modo perfección de los colores, ya que cada cosa se llama perfecta en la medida en que está en acto, así como se dice imperfecto lo que existe solo en potencia, razón por la cual, como el intelecto agente hace en acto la multitud de especies inteligibles, mientras que el posible solo en potencia, aquél se dice perfecto, éste imperfecto” (Faba 1597, 708).

El texto 19 está referido a las notas del intelecto (Faba las llama affectionibus), y comienza con la cláusula aristotélica: "Y tal intelecto es separable, sin mezcla e impasible, siendo como es acto por su propia entidad". La primera nota -separado- la interpreta en el sentido de que "el intelecto 
es separable del cuerpo... lo cual se puede entender de toda la parte intelectiva" (Faba 1597, 709), es decir, tanto del agente como del posible. De la segunda y tercera -inmixto e impasible- declara que el intelecto (término en que incluye los dos) "no está compuesto de cosas materiales o corpóreas ni puede padecer, a saber, con pasión corruptiva” (Faba 1597, 709). De la cuarta -acto por su propia entidad-, indica que en esta nota se distingue el intelecto agente del posible. De la expresión "y es que siempre es más excelso el agente que el paciente, el principio que la materia”, afirma que "aquello que puede el intelecto posible también lo podrá el agente... porque todo agente es más noble que el paciente, como la causa eficiente es más noble que la material" (Faba 1597, 710).

El texto 20 trata de la distinción de ambos intelectos respecto de otras facultades del alma. Del pasaje "Por lo demás, la misma cosa son la ciencia en acto y su objeto", Agustín Faba refiere que es la primera diferencia que Aristóteles pone entre el intelecto agente y el posible, a saber, que el intelecto posible siempre es distinto de las realidades inteligibles, mientras que el agente no se distingue de la realidad entendida (Faba 1597, 711). La segunda diferencia -añade- es que el intelecto posible siempre es anterior al agente según el tiempo, y Aristóteles la expresa mediante la cláusula “desde el punto de vista de cada individuo la ciencia en potencia es anterior en cuanto al tiempo". De la siguiente sentencia del Estagirita, "pero desde el punto de vista del universo en general no es anterior ni siquiera en cuanto al tiempo", Faba indica que Aristóteles asegura en el libro IX de la Metafísica que el acto siempre es previo a la potencia, y que ésta siempre se reduce al acto por algo extrínseco que está en acto, como sucede en el caso de la ciencia que adquiere el discípulo por la educación del maestro (Faba 1597, 711-712). En cuanto a la expresión "no ocurre, desde luego, que el intelecto entienda a veces y a veces deje de entender", indica que "el intelecto agente puede entender y contemplar cuando quiere, y desistir de su acción cuando quiere, pero el posible no puede contemplar siempre que quiere, ya que carece de las especies inteligibles en acto, pues solo tiene potestad de recibir las mismas especies" (Faba 1597, 712). En cuanto a lo siguiente, a saber, que "una vez separado es sólo aquello que en realidad es y únicamente esto es inmortal 
y eterno", Faba dice que eso es propio del alma intelectiva, por lo que ella se distingue de las demás potencias corpóreas (vegetativas y sensitivas), y añade que por "eterna" no se debe entender que haya sido siempre, sino que siempre será (Faba 1597, 712). En cuanto a la expresión: "Nosotros, sin embargo, no somos capaces de recordarlo, porque tal principio es impasible", indica que el alma no recuerda lo que conocía cuando estaba unida al cuerpo, porque recordar pertenece a la parte sensitiva del alma, que es perecedera (Faba 1597, 713). Sin embargo, esta interpretación fabiana -a distinción de las precedentes- no es correcta, porque además de memoria sensible también disponemos de memoria intelectual. Por último, de la dicción "mientras que el intelecto pasivo es corruptible y sin él nada entiende", señala que tal intelecto es la fantasía, y concluye con una tesis aporética, a saber, "el alma no puede conocer nada sin su operación, sino que entiende con el auxilio de la fantasía, potencia que como siempre permanece en el cuerpo, hace que el alma fuera del cuerpo carezca de fantasmas y no pueda entender. De aquí se deduce que no es acción propia del alma sino también común al cuerpo” (Faba 1597, 713).

Nótese que, pese al pormenorizado comentario literal al texto, bastante certero por cierto, Agustín Faba no se ha pronunciado acerca de la específica naturaleza del intelecto agente. En efecto, nos deja con la pregunta de si lo entiende como una "potencia", como una "virtud", como un "acto" y qué "tipo de acto", meramente como una "parte del alma”. Por lo mismo, tampoco queda clara si su distinción respecto del intelecto posible es "real” o exclusivamente "formal", aunque en un texto parece inclinarse por esto último: "el intelecto posible y el agente son el mismo sujeto (sint subiecto idem), y nada es causa eficiente de sí, sino de otra realidad (las especies) que se distingue según el género o la especie del principio eficiente” (Faba 1597, 708).

\section{Conclusiones}

De este estudio referido al intelecto agente en los diversos pensadores tenidos en cuenta del s. XVI podemos sacar las siguientes conclusiones:

a) Unos de ellos -como Durando en el s. XIV-negaron la distinción real entre uno y otro intelecto: Jacques Lefèvre d’Étaples, Francisco Suárez y Gabriel Vázquez. 
b) Otros fueron -como en el s. XIII Escoto-formalistas, es decir, admitieron que entre el intelecto agente y el posible sólo se da una distinción formal o de razón: Felipe Melanchton, Juan Velcurio y Rodolfo Goclenio.

c) Otros fueron -como Ockham en el s. XIV- más bien nominalistas, esto es, aceptaron que entre intelecto agente y posible sólo se da una distinción nominal: Gómez Pereira, el Brocense, Juan Eck y Agustín Faba.

Por último, cabe indicar que estas tres tesis no son correctas, ni en la exégesis del texto aristotélico, ni en sus afirmaciones sobre la realidad del intelecto agente. Esto último por tres motivos: a) porque la distinción entre ambos intelectos es real, es decir, se trata de dos dimensiones noéticas humanas jerárquicamente distintas entre sí, pues sin la inmaterial activa no se puede activar la inmaterial pasiva (tabula rasa); b) porque la distinción no es meramente de razón, atribuida a los diversos oficios o actos, ya que todos éstos se predican del intelecto posible (abstraer, conceptualizar, juzgar...) una vez que éste es activado por el agente, y c) porque la distinción no en meramente de nombres, pues "agente" y "posible" se predican de realidades noéticas nativas distintas, siendo una de orden predicamental, por potencial, el posible o paciente, y otra de nivel trascendental, el agente.

\section{Referencias}

Alejandro, J. M. 1948. “Esencia y valor del conocimiento según el Dr. Eximio.” Miscelanea Comillas 9: 211-246.

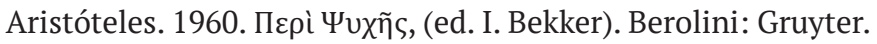

Baciero, F. 2006. “El entendimiento agente en Gabriel Vázquez”. En El entendimiento agente en la Escolástica Renacentista, editado por J. F. Sellés, 247-272. Pamplona: Eunsa.

Eckii, I. 1520. Aristotelis Stagyritae Philosophi De anima libri III, De sensu et sensato, De memoria et reminiscencia, De somno et vigilia, De longitidine et brevitate vitae, per Argyropoulum ex antique traductionesm, adiectis Eckii commentariis. Augustae Vindelicorum: Sigmund Grimm \& Marx Wirsung.

Fabae Savilianensis, A. 1597. In tres Aristotelis libros De anima. Augusta Taurinorum. 
Faber Stapulensis, J. 1501. In hoc opere continetur totius philosophiae naturalis paraphrases. Pariis: Volffgangum Hopylium.

Goclenii, R. 1589. De intellectu, et aliis quibusdam. Marpurgi Cattorum.

Goclenii, R. 1594. Adversaria ad exotericas aliquod Iulii Caesaris Scaligeri acutissimi philosophi exercitationes. Marpurgi : Typis Pauli Egenolphi.

Goclenii, R. 1598. Physicae Disputationes septem libros distinctae. Francofurt : M. Zacharias Palthenius Typographus.

Goclenii, R. 1604. Physica Complete Speculum. Marpurgi : ex Collegio Palcheniano.

Grau, A. 2002. “El entendimiento agente en Francisco Suárez.” Revista Española de Filosofía Medieval 9 (2002): 185-204.

Melanchton, F. 1846. Corpus Reformatorum Melanchthonis Opera, vol. 13. Frankfurt am Main: Minerva, GMBH.

Menéndez Pelayo, M. 1955. La filosofía española. Madrid: Rialp.

Sevilla, R. 2006. "El entendimiento agente en la gnoseología de Francisco Suárez.” En El entendimiento agente en la Escolástica Renacentista, editado por J. F. Sellés, 273-300. Pamplona: Eunsa.

Sellés, J. F. 2012. El intelecto agente y los filósofos. Venturas y desventuras del supremo hallazgo aristotélico sobre el hombre (I). Pamplona: Eunsa.

Suárez, F. 1856-1978. Opera Omnia. Paris: Ludovicum Vivés, vols. 1-26.

Suárez, F. 1859. De anima. En Opera omnia: vol. 3. París: Ludovicum Vivés.

Vázquez, G. 1598. Commentariorum ac disputationum in Primam Partem S. Thomae. Compluti: Ex officina Ioannis Gratiani.

Velcurionis, I. 1575. Commentariorum libri IIII in universam aristotelis Phisicen. Coloniae Agripinae: Excudebat Petrus Horft. 